Tropical Journal of Pharmaceutical Research August 2012; 11 (4): 577-583

(c) Pharmacotherapy Group, Faculty of Pharmacy, University of Benin Benin City, 300001 Nigeria.

All rights reserved.

Available online at http://www.tjpr.org

Research Article

http://dx.doi.org/10.4314/tjpr.v11i4.8

\title{
Preparation and In-vitro Evaluation of Metformin Microspheres Using Non-Aqueous Solvent Evaporation Technique
}

\author{
Navneet Garud and Akanksha Garud
}

Institute of Professional Studies- College of Pharmacy, Shivpuri Link Road, Gwalior (MP), India.

\begin{abstract}
Purpose: To prepare and evaluate metformin microspheres for prolonged release.

Methods: Metformin microspheres were prepared by non-aqueous solvent evaporation method using various polymers, including ethylcellulose (EC), hydroxypropyl methylcellulose (HPMC), carbopol 934P $(\mathrm{CA})$ and chitosan $(\mathrm{CH})$. The effect of process variables, viz, drug/polymer ratio, stirring rate and type of polymer on the mean particle size, drug entrapment efficiency, yield, drug content, micromeritic properties and drug release of the microspheres were studied.

Results: It was observed that as the stirring speed increased from 600 to $1800 \mathrm{rpm}$, microsphere size decreased and hence drug release rate increased. Drug release rate at 1:2 drug: polymer for microspheres produced at a stirring rate of $1200 \mathrm{rpm}$ was in the following order: carbopol 934P > HPMC $>$ ethyl cellulose > chitosan. The formulations containing carbopol 934P (CA3) and HPMC (HPMC3) released drug faster than chitosan microspheres (CH3).

Conclusion: Amongst the developed microspheres, $\mathrm{CH} 3$ formulation (with chitosan as the polymer) exhibited maximum prolonged drug release at gastrointestinal $\mathrm{pH}$ or at least $15 \mathrm{~h}$. This oral sustained metformin formulation could potentially improve the bioavailability of the drug as well as patient compliance.
\end{abstract}

Keywords: Metformin, Microspheres, Prolonged release, Solvent evaporation, Ethylcellulose, Hydroxypropyl methylcellulose, Chitosan 


\section{INTRODUCTION}

Microspheres have gained wide acceptance as a means to achieve oral and parenteral controlled drug delivery systems. They often require a polymer as carrier as well as core material [1]. Among the various methods developed for the formulation of microspheres, the solvent evaporation method has gained much attention due to its ease of fabrication without compromising the activity of the drug.

Ethyl cellulose, a non-ionic, inert hydrophobic, non-biodegradable and biocompatible polymer with minimal toxicity. It is one of the extensively studied encapsulating materials for the controlled release of pharmaceuticals [2]. HPMC is a non-ionic, swellable polymer. Hydrophilic polymer gel matrix systems are widely used in controlled drug delivery to obtain a desirable drug release profile and cost effectiveness because of their flexibility. The hydration rate of HPMC increases with increase in the hydroxypropyl content. Carbopol is a polymer consisting of acrylic acid cross-linked with either polyalkenyl ether or divinyl glycol. It readily absorbs water, gets hydrated and swell. In addition to its hydrophilic nature, cross-linked structure and insolubility in water, carbopol is an anionic polymer, and hence a potential candidate for use in controlled release drug delivery [3].

The use of natural polymers is preferred due to their proven biocompatibility and safety. In this respect, chitosan, a cationic polymer, has attracted particular attention. It is biocompatible, biodegradable and bioadhesive at physiological $\mathrm{pH}$ and possesses $\mathrm{OH}$ and $\mathrm{NH}_{2}$ groups that can give rise to hydrogen bonding. It is a high molecular weight polysaccharide, comprising of glucosamine and $\mathrm{N}$-acetyl glucosamine obtained by deacetylation of chitin [4]. Because of its low production cost, non-toxic nature, and FDA approval, chitosan has found application in multiparticulate drug delivery [5].
Diabetes mellitus (DM) is the name given to a group of disorders characterized by chronic hyperglycemia, polyurea, polydipsia, polyphagia, emaciation and weakness due to disturbance in carbohydrate, fat and protein metabolism associated with absolute or relative deficiency in insulin secretion and/or insulin action. A drug of choice, either alone or in combination with other hypoglycemic agents, particularly in Type II diabetes, metformin, is an effective antidiabetic drug, belonging to the biguanide class [6].

\section{EXPERIMENTAL}

\section{Materials}

Metformin hydrochloride was received as a gift from Sun Pharmaceuticals, Baroda, India. Acetone and liquid paraffin (Merck Ltd, Mumbai, India), ethylcellulose (EC, S.D. Fine Chemicals, Mumbai, India), hydroxypropyl methylcellulose (HPMC-E15) and carbopol934P (CA) (Central Drug House, Mumbai, India), chitosan $(\mathrm{CH}$, medium viscosity grade, Central Institute of Fisheries Technology, Cochin, India. All other chemicals and deionised water used were of analytical grade.

\section{Preparation of microspheres}

The microspheres containing the anti-diabetic drug, metformin, as the core material were prepared by a non-aqueous solvent evaporation method [7]. Here, the drug (250 $\mathrm{mg})$ and the polymers $(250,500$, or $750 \mathrm{mg}$ ) were mixed in acetone $(8 \mathrm{ml})$ at various ratios. The slurry was introduced into $30 \mathrm{ml}$ of liquid paraffin while stirring $(600,1200$ or $1800 \mathrm{rpm}$ ) with a mechanical stirrer equipped with a three-blade propeller at room temperature. The solution was stirred for $4 \mathrm{~h}$ to allow the solvent to evaporate and the microspheres were collected by filtration by Whatman filter paper no. 1. The microspheres were washed repeatedly with petroleum ether $\left(40-60{ }^{\circ} \mathrm{C}\right)$ until free from oil. The microspheres were collected and dried for $3 \mathrm{~h}$ at room temperature and 
subsequently stored in a desiccator over fused calcium chloride.

The effect of process variables including drug/polymer ratio, stirring rate and polymer type on mean microsphere size, drug entrapment efficiency, yield, drug content, micromeritic properties and drug release was studied. Metformin microspheres were prepared in varying drug/polymer ratio (see Table 1) while keeping stirring speed (1200 rpm) constant. Similarly, microspheres were prepared at various stirring rates (i.e., 600, 1200 and $1800 \mathrm{rpm}$ ) while keeping drug/polymer ratio constant at 1:2.

\section{Evaluation of micromeritic properties of microspheres}

The microspheres were characterized for their micromeritic properties - angle of repose, bulk density, tapped density, Carr's index, and Hausner's ratio [7,8]. Angle of repose $(\theta)$ of different formulations was measured according to the fixed funnel standing method $(n=3)$ and calculated using Eq 1.

$\theta=\tan ^{-1} \mathrm{~h} / \mathrm{r}$

where $r$ is the radius of the cone base, and $h$ the height of the base.

Bulk and tapped densities were measured using a $10 \mathrm{ml}$ graduated cylinder. The sample placed in the cylinder and the volume (bulk) noted. The cylinder was then,tapped 100 times and the volume (tapped) again noted. The bulk and tapped densities were calculated were calculated from the ratio of the weight and volume as appropriate. Compressibility (Carr's) index (Ci) of microparticles was computed according to Eq 2.

$\mathrm{Ci}=(\mathrm{Dt}-\mathrm{Db}) / \mathrm{Dt} \times 100$

where $\mathrm{Dt}$ is tapped density and $\mathrm{Db}$ the bulk density.

Hausner's ratio of the microparticles was determined as in Eq 3.

Hausner's ratio $=\mathrm{Dt} / \mathrm{Db}$

\section{Morphology and particle size}

The shape and surface characteristics of the microspheres were studied using scanning electron microscope (SEM, LEO - 430, Leo Electron Microscopy Ltd., Cambridge, England). The microparticles were coated uniformly with gold-palladium by using a sputter coater (Polaron SC-76430) after fixing the sample in individual stubs. The operating parameters were an acceleration voltage of $20 \mathrm{kV}$ and chamber pressure of $0.6 \mathrm{~mm} \mathrm{Hg}(\mathrm{n}$ $=3$ ). Size distribution based on mean diameter of the microspheres was determined by optical microscopy method $[8,9]$. Approximately, 100 microspheres were counted using a calibrated optical microscope (Magnus MLX-DX) and mean particle size was calculated.

\section{Evaluation of entrapment efficiency, drug loading and yield}

Microspheres $(50 \mathrm{mg})$ were treated with 50 $\mathrm{ml}$. of phosphate buffer ( $\mathrm{pH} \mathrm{6.8)}$, in $100 \mathrm{ml}$. amber coloured vial with stirring at $250 \mathrm{rpm}$. The temperature was maintained at $37 \pm 0.2$ ${ }^{\circ} \mathrm{C}$. At the end of $2 \mathrm{~h}$, it was filtered and the filtrate analyzed spectrophotometrically ( $\mathrm{n}=$ 3) at $232 \mathrm{~nm}$ (Shimadzu, Pharmspec UV1700 series, Japan). Drug entrapment efficiency, drug loading and yield were were calculated using Eqs 4 - 6 [10].

Drug entrapment $(\%)=(A / T) 100 \ldots .$.

where $A$ is actual drug concentration and $T$ is the theoretical drug concentration.

Drug loading $(\%)=(\mathrm{Wd} / \mathrm{Wm}) 100$

where $\mathrm{Wd}$ is the weight of drug and $\mathrm{Wm}$ the weight of the microspheres.

Yield $(\%)=(W m / W d p) 100$

where $W d p$ is the expected total weight of drug and polymer. 


\section{In-vitro drug release studies}

The in-vitro drug release profiles of the various microsphere formulations were studied in $900 \mathrm{ml}$ of buffer in simulated gastrointestinal $\mathrm{pH}$ conditions, viz, simulated gastric fluid $(0.1 \mathrm{M} \mathrm{HCl}, \mathrm{pH} 1.2)$ for the first 2 $\mathrm{h}$ followed by $4 \mathrm{~h}$ in simulated intestinal fluid (phosphate buffer solution, PBS, pH 6.8) and finally for $9 \mathrm{~h}$ in simulated intestinal fluid (phosphate buffer solution, PBS, pH 7.4) [11]. Samples $(5 \mathrm{ml})$ were withdrawn at various time intervals, and replaced with the same volume of test medium to maintain sink conditions. The withdrawn samples were diluted, where necessary, filtered through a $0.45 \mu$ membrane filter and analyzed for metformin content at $232 \mathrm{~nm}$ using Shimadzu spectrophotometer (Pharmspec UV-1700 series, Japan).

\section{Statistical analysis}

Experimental results $(n=3)$ were expressed as mean \pm S.D. One-way ANOVA was performed using Sigma Stat software (SPSS Inc, USA) for Windows, version 2.30. Differences were considered significant at $p<$ 0.05 .

\section{RESULTS}

\section{Particle characteristics}

Scanning electron microphotographs showed that the microspheres were spherical with a smooth to rough surface (Fig 1). Pores were observed on the microsphere surface. Increasing polymer concentrations (i.e., drugpolymer ratio from $1: 1$ to $1: 3$ ) increased microsphere size from $352.1 \pm 7.5$ to $374.2 \pm$ $7.8 \mu \mathrm{m}$ for ethylcellulose, $359.3 \pm 4.1$ to 388.4 $\pm 8.8 \mu \mathrm{m}$ for HPMC, $424.5 \pm 8.6$ to $450.3 \pm$ $8.8 \mu \mathrm{m}$ for carbopol 934P, and $408.6 \pm 10.6$ to $426.8 \pm 8.2 \mu \mathrm{m}$ for chitosan. However, in all cases, the increase was not significant $(p>$ 0.05).

Increase in stirring rate from $600 \mathrm{rpm}$ to 1800 rpm also seemed to have decreased microsphere size but the decrease was not significant $(p>0.05)$.

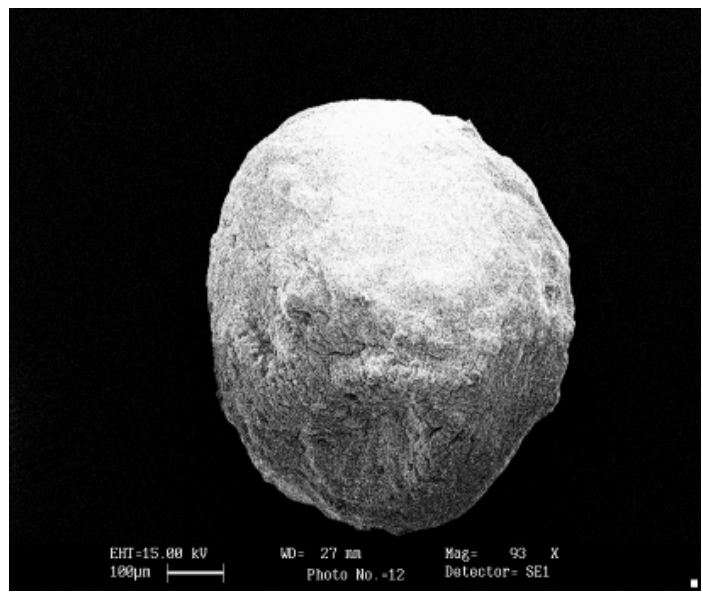

Fig 1: Scanning electron microphotographs (SEM) of metformin microspheres prepared with HPMC using solvent evaporation method

Microsphere yield was > $56.8 \%$ for all the formulations while entrapment efficiency (\%) ranged $56.4 \pm 2.4$ to $85.4 \pm 3.4$ for EC microspheres, $68.1 \pm 4.2$ to $85.5 \pm 3.9$ for HPMC microspheres, $64.1 \pm 4.8$ to $85.2 \pm 5.3$ for CA microspheres and $61.2 \pm 3.3$ to $83.5 \pm$ 5.1 for $\mathrm{CH}$ microspheres (Table 1 ).

\section{Micromeritic properties of microspheres}

All the formulations showed angle of repose in the range of $25^{\circ}$ to $34^{\circ}$. Compressibility, i.e., Carr's index, was between 11.0 and 15.5 $\%$ and Hausner's ratio < 1.2, all the parameters indicating good flow property. Of particular note are formulations EC5 and CA5 which showed the best flow properties (Table 2).

\section{In-vitro drug release of microspheres}

Drug release (for 1:3 drug/polymer ratio) after $15 \mathrm{~h}$ was in the rank order: carbopol 934P > HPMC > ethyl cellulose > chitosan (Fig 2), with the formulation prepared with carbopol 934P releasing approximately $94.8 \%$ of drug after $15 \mathrm{~h}$.

Trop J Pharm Res, August 2012;11 (4):580 
Table 1: Characteristics of metformin microspheres prepared using solvent evaporation method (mean \pm $\mathrm{SD}, \mathrm{n}=3$ )

\begin{tabular}{llllll}
\hline Batch & $\begin{array}{l}\text { Drug:polymer } \\
\text { ratio }\end{array}$ & $\begin{array}{l}\text { Stirring speed } \\
\text { (rpm) }\end{array}$ & $\begin{array}{l}\text { \% } \\
\text { content }\end{array}$ & $\begin{array}{l}\text { Drug } \\
\text { efficiency (\%) }\end{array}$ & Yield (\%) \\
\hline EC1 & $1: 1$ & 1200 & 42.1 & $67.85 \pm 6.1$ & 56.8 \\
EC2 & $1: 2$ & 1200 & 34.6 & $78.68 \pm 4.3$ & 59.8 \\
EC3 & $1: 3$ & 1200 & 26.5 & $85.42 \pm 3.4$ & 65.3 \\
EC4 & $1: 2$ & 600 & 28.2 & $56.36 \pm 2.4$ & 62.5 \\
EC5 & $1: 2$ & 1800 & 29.5 & $72.21 \pm 1.3$ & 58.8 \\
HPMC1 & $1: 1$ & 1200 & 43.7 & $69.23 \pm 2.8$ & 64.9 \\
HPMC2 & $1: 2$ & 1200 & 45.3 & $73.92 \pm 4.8$ & 71.8 \\
HPMC3 & $1: 3$ & 1200 & 25.8 & $85.54 \pm 3.9$ & 78.3 \\
HPMC4 & $1: 2$ & 600 & 27.5 & $68.13 \pm 4.2$ & 72.8 \\
HPMC5 & $1: 2$ & 1800 & 28.6 & $71.8 \pm 2.2$ & 66.1 \\
CA1 & $1: 1$ & 1200 & 44.8 & $70.23 \pm 3.9$ & 68.7 \\
CA2 & $1: 2$ & 1200 & 47.1 & $76.92 \pm 6.0$ & 72.2 \\
CA3 & $1: 3$ & 1200 & 26.2 & $85.22 \pm 5.3$ & 83.2 \\
CA4 & $1: 2$ & 600 & 28.4 & $64.12 \pm 4.8$ & 76.5 \\
CA5 & $1: 2$ & 1800 & 29.8 & $67.87 \pm 2.4$ & 70.2 \\
CH1 & $1: 1$ & 1200 & 37.6 & $62.23 \pm 3.3$ & 59.7 \\
CH2 & $1: 2$ & 1200 & 40.2 & $78.29 \pm 4.8$ & 71.4 \\
CH3 & $1: 3$ & 1200 & 23.6 & $83.51 \pm 5.1$ & 82.3 \\
CH4 & $1: 2$ & 600 & 28.7 & $69.23 \pm 3.3$ & 73.8 \\
CH5 & $1: 2$ & 1800 & 30.6 & $61.23 \pm 3.3$ & 68.9 \\
\hline
\end{tabular}

Key: $\mathrm{EC}=$ ethylcellulose, $\mathrm{HPMC}=$ hydroxypropyl methylcellulose, $\mathrm{CA}=$ carbopol $934 \mathrm{P}$, and $\mathrm{CH}=$ chitosan, microspheres

Table 2: Some micromeritic properties of the formulations

\begin{tabular}{|c|c|c|c|c|c|c|}
\hline Batch & $\begin{array}{l}\text { Average } \\
\text { particle size } \\
(\mu \mathrm{m})\end{array}$ & $\begin{array}{l}\text { Tapped } \\
\text { density } \\
\left(\mathrm{g} / \mathrm{cm}^{3}\right)\end{array}$ & $\begin{array}{l}\text { Bulk } \\
\text { density } \\
\left(\mathrm{g} / \mathrm{cm}^{3}\right)\end{array}$ & $\begin{array}{l}\text { Carr's index } \\
(\%)\end{array}$ & $\begin{array}{l}\text { Hausner's } \\
\text { ratio }\end{array}$ & $\begin{array}{l}\text { Angle of } \\
\text { repose }\end{array}$ \\
\hline EC1 & $352.1 \pm 7.5$ & 0.720 & 0.625 & 13.19 & 1.15 & $31^{\circ} 12^{\prime}$ \\
\hline EC2 & $361.4 \pm 6.2$ & 0.663 & 0.582 & 12.22 & 1.14 & $29^{\circ} 18^{\prime}$ \\
\hline EC3 & $374.2 \pm 7.8$ & 0.659 & 0.568 & 13.81 & 1.16 & $27^{\circ} 34^{\prime}$ \\
\hline EC4 & $396.5 \pm 7.6$ & 0.608 & 0.514 & 15.46 & 1.18 & $25^{\circ} 43^{\prime}$ \\
\hline EC5 & $338.1 \pm 4.5$ & 0.627 & 0.556 & 11.35 & 1.13 & $33^{\circ} 52^{\prime}$ \\
\hline HPMC1 & $359.3 \pm 4.1$ & 0.675 & 0.588 & 12.89 & 1.15 & $32^{\circ} 14^{\prime}$ \\
\hline HPMC2 & $375.6 \pm 6.2$ & 0.647 & 0.563 & 12.98 & 1.15 & $29^{\circ} 26^{\prime}$ \\
\hline HPMC3 & $388.4 \pm 8.8$ & 0.625 & 0.548 & 12.32 & 1.14 & $27^{\circ} 42^{\prime}$ \\
\hline HPMC4 & $410.2 \pm 6.4$ & 0.566 & 0.486 & 14.13 & 1.17 & $26^{\circ} 27^{\prime}$ \\
\hline HPMC5 & $352.6 \pm 5.2$ & 0.583 & 0.516 & 11.49 & 1.13 & $33^{\circ} 88^{\prime}$ \\
\hline CA1 & $424.5 \pm 8.6$ & 0.617 & 0.535 & 13.29 & 1.15 & $30^{\circ} 20^{\prime}$ \\
\hline CA2 & $432.1 \pm 9.2$ & 0.584 & 0.512 & 12.33 & 1.14 & $29^{\circ} 12^{\prime}$ \\
\hline CA3 & $450.3 \pm 8.8$ & 0.556 & 0.489 & 12.05 & 1.14 & $27^{\circ} 24^{\prime}$ \\
\hline CA4 & $484.7 \pm 4.2$ & 0.497 & 0.424 & 14.69 & 1.17 & $26^{\circ} 45^{\prime}$ \\
\hline CA5 & $412.5 \pm 5.6$ & 0.516 & 0.458 & 11.36 & 1.13 & $31^{\circ} 81^{\prime}$ \\
\hline $\mathrm{CH} 1$ & $408.6 \pm 10.6$ & 0.562 & 0.482 & 14.23 & 1.17 & $33^{\circ} 18^{\prime}$ \\
\hline $\mathrm{CH} 2$ & $417.2 \pm 5.8$ & 0.550 & 0.474 & 13.82 & 1.16 & $31^{\circ} 24^{\prime}$ \\
\hline $\mathrm{CH} 3$ & $426.8 \pm 8.2$ & 0.539 & 0.466 & 13.54 & 1.16 & $29^{\circ} 82^{\prime}$ \\
\hline $\mathrm{CH} 4$ & $458.1 \pm 5.7$ & 0.490 & 0.416 & 15.28 & 1.18 & $27^{\circ} 65^{\prime}$ \\
\hline $\mathrm{CH} 5$ & $385.7 \pm 6.8$ & 0.505 & 0.441 & 12.74 & 1.15 & $33^{\circ} 91^{\prime}$ \\
\hline
\end{tabular}




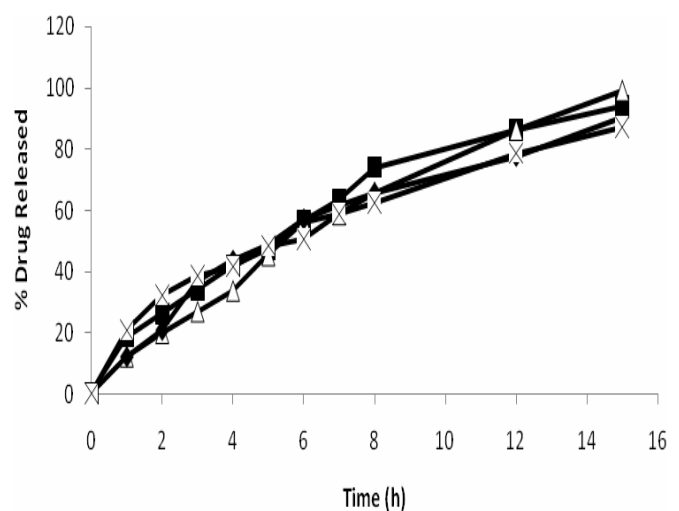

Fig 2: Metformin release from microspheres (1:3 drug:polymer) ratio. Key: $=\mathrm{EC}, \Delta=\mathrm{HPMC}$, $\mathrm{CA}, x=\mathrm{CH}$

Increase in stirring speed from $600 \mathrm{rpm}$ to $1800 \mathrm{rpm}$ enhanced drug release rate. At $1800 \mathrm{rpm}$, complete drug release was observed except for chitosan microspheres. Fig 3 shows that the difference in drug release pattern among the various polymer types was not significant $(p>0.05)$.

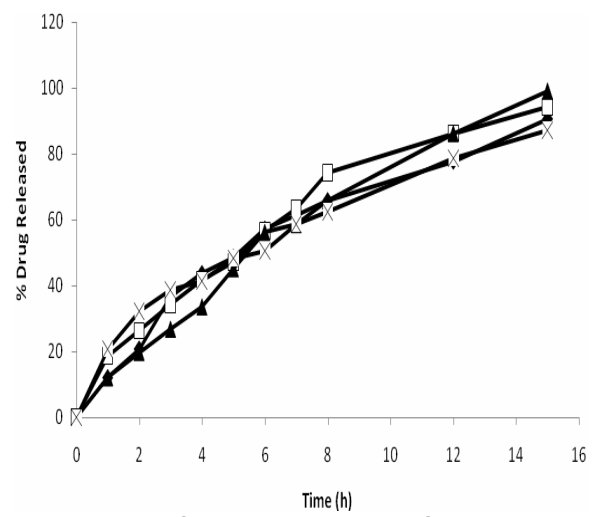

Fig 3: Metformin release from microspheres prepared at stirring speed of $1200 \mathrm{rpm}$ by solvent evaporation method (Key: $\downarrow=\mathrm{EC},=\mathrm{HPMC}, \boldsymbol{\Delta}=$ $\mathrm{CA}, \mathrm{x}=\mathrm{CH}$ ).

\section{DISCUSSION}

Increase in polymer concentration from 1:1 to 1:3 (drug:polymer) increased yield and entrapment efficiency probably because with increasing polymer content, more particles of metformin would be coated leading to higher encapsulation efficiency [12]. However, this increase was not significant.

The pores on the microsphere surface of some formulations indicate leaching of the drug during dissolution prior to gelation of the polymeric surface. It was observed that as the drug-polymer concentration increased, the percentage entrapment efficiency increased whereas the percentage yield decreased.

Increase in the particle size of the microspheres can be attributed to increase in viscosity with increasing polymer concentrations, which resulted in large emulsion droplets $[13,14]$. Shearing efficiency during stirring also diminishes at higher viscosities, thus resulting in the formation of larger droplets and hence bigger particles [15].

As drug:polymer ratio was varied from $1: 1$ to $1: 3$, with the consequent increase in the polymer content, drug release rate gradually decreased. The increased density of the polymer matrix at higher polymer concentrations results in increased diffusional pathway decreasing overall drug release from the polymer matrix [17]. Furthermore, smaller microspheres formed at lower polymer concentrations have a larger surface area exposed to the dissolution medium, thus leading faster drug release. The microspheres prepared with EC, HPMC and CA completely released the drug after $12 \mathrm{~h}$. However, sustained drug release was observed for microspheres formulated with chitosan polymer extending to $15 \mathrm{~h}$.

The drug release was slower at acid $\mathrm{pH}$ than at alkaline $\mathrm{pH}$. However, when chitosan was used as the polymer, more drug was released $(34 \%)$ at acid $\mathrm{pH}$ in $2 \mathrm{~h}$ at a stirring speed of $1800 \mathrm{rpm}$. This is due to the increased solubility of chitosan at acid $\mathrm{pH}$. 


\section{CONCLUSION}

Varying degrees of sustained metformin release were obtained for microspheres formulated $\mathrm{EC}, \mathrm{HPMC}, \mathrm{CA}$ and $\mathrm{CH}$ with $\mathrm{CH}$ microspheres being the most drug sustaining of them all. Therefore, the developed formulations, prepared by non-aqueous solvent evaporation method, are promising for the sustained oral delivery of metformin hydrochloride.

\section{ACKNOWLEDGEMENT}

The authors are grateful to Sun Pharmaceuticals, Baroda, India for providing, free of charge, the sample of metformin hydrochloride used in the study.

\section{REFERENCES}

1. Behera BC, Sahoo SK, Dhal S, Barik BB, Gupta BK. Characterization of glipizide-loaded polymethacrylate microspheres prepared by an emulsion solvent evaporation method. Tropical Journal of Pharmaceutical Research 2008; 7(1): 879-885

2. Das MK, Rao KR. Evaluation of zidovudine encapsulated ethyl cellulose microspheres prepared by water-in-oil-in-oil (w/o/o) double emulsion solvent diffusion technique. Acta Poloniae Pharmaceutica - Drug Research 2006; 63(2): 141-148

3. Carnali JO, Naser MS. The Use of Dilute Solution Viscosity to Characterize the Network Properties of Carbopol Microgels. Colloid and Polymer Science 1992; 270(2): 183-193

4. Mishra B, Jayanth $P$, Sankar C. Development of chitosan-alginate microcapsules for colon specific delivery of metronidazole. Indian Drugs 2003; 40(12): 695-700

5. Dubey RR, Parikh RH. Two stage optimization process for formulation of chitosan microspheres. AAPS Pharm Sci Tech 2004; 5(1), Article 5

6. Choudary PK, Kar M. Preparation of alginate gel beads containing metformin hydrochloride using emulsion-gelation method. Tropical
Journal of Pharmaceutical Research 2005; 4(2): 489-493

7. Chowdary KPR, Rao YS. Mucoadhesive microcapsules of glipizide: characterization, in vitro and in vivo evaluation. Indian J Pharm Sci 2003; 65(3): 279-284

8. Lachman L, Lieberman HA, Kanig JL. The theory and practice of industrial pharmacy, $4^{\text {th }}$ ed. Mumbai Varghese Publishing House 1991; pp 183-184

9. Martin A, Bustamante P, Chun AHC. Physical Pharmacy: Physical chemical principles in the pharmaceutical sciences, $4^{\text {th }}$ ed. B.I. Publications Pvt. Ltd. 2005; pp 423-448

10. Sengel CT, Hascicek C, Gonul N. Development and in-vitro evaluation of modified release tablets including ethylcellulose microspheres loaded with diltiazem hydrochloride. J Microencapsulation 2006; 23(2): 135-152

11. Bhagwat DA, Bhutkar MA, Todkar SS, Mohite SK, Gattani YS. Formulation and evaluation of controlled release microspheres of isosorbide dinitrate. Int J Pharm Tech Res 2009; 1(2): 125-128

12. Khan SA, Ahmad M, Murtaza G, Aamir MN, Rehman N, Kousar R, Rasool F, Akhtar M. Formulation of Nimesulide Floating Microparticles Using Low-viscosity Hydroxypropyl Methylcellulose. Trop J Pharm Res 2010; 9 (3): 293-299

13. Vasir JK, Tambwekar K, Garg S. Bioadhesive microspheres as a controlled drug delivery system, Int J Pharm 2003; 255: 13-32

14. Jain SK, Rai G, Saraf DK, Agrawal GP. The preparation and evaluation of albendazole microsphere for colonic delivery. Pharm Technol 2004; 28(12): 66-71

15. Lee JH, Park TG, Choi HK. Effect of formulation and processing variables on the characteristics of microspheres for water-soluble drugs prepared by w/o/o double emulsion solvent diffusion method. Int J Pharm 2000; 196: 75-83

16. Khan MS, Gowda DV, Bathool A. Formulation and characterization of Piroxicam floating microspheres for prolonged gastric retention. Der Pharmacia Lettre 2010; 2(6): 217-222

17. Ramachandran S, Shaheedha SM, Thirumurugan G, Dhanaraju MD. Floating Controlled Drug Delivery System of Famotidine Loaded Hollow Microspheres (Microballoons) in the Stomach. Curr Drug Delivery 2010; 7: 93-97 